\title{
APLICAÇÕES E IMPLICAÇÕES DA ANÁLISE DO COMPORTAMENTO NO CONTEXTO EDUCACIONAL E DA SAÚDE
}

Fernanda Torres Sahão

Universidade Estadual de Londrina

\section{Publicação}

Melo, C. M. (Org.); Luzia, J. C. (Org.); Kienen, N. (Org.); Fornazari, S. A. (Org.). (2015). Psicologia e Análise do Comportamento: Saúde e processos educativos. 1a. ed. Londrina: UEL

\section{RESENHA}

Você estuda Psicologia, mas não se imagina trabalhando em uma sala fechada e por conta própria? Você lê, ouve, presencia situações difíceis em diversos contextos no seu cotidiano e queria poder fazer algo a respeito, para mudar aquela realidade? Cansou de explicar para os amigos e família que o Psicólogo não "lê mentes" e não fica "analisando" os outros o tempo todo? Se você respondeu sim para alguma dessas perguntas, o livro "Psicologia e Análise do Comportamento: Saúde e processos educativos" pode te ajudar. A obra aborda dois contextos que se caracterizam pela atuação multidisciplinar, nos quais o psicólogo pode se inserir e desenvolver um trabalho diferente da visão restrita que se pode ter do que é "ser psicólogo". Com linguagem acessível, temas variados e excelentes autores com atuação em diversas áreas, a leitura dessa obra é de grande valor para a formação e desenvolvimento de profissionais interessados na promoção de qualidade de vida e conhecimento para a população em geral.

O psicólogo vem desenvolvendo práticas que vão além do contexto clínico há um tempo e ao inserir-se em ambientes caracterizados pela diversidade de profissionais, como hospitais e escolas, pode enfrentar obstáculos para os quais não se sente preparado. Essa realidade pode trazer algumas dúvidas sobre o que fazer ao se deparar com determinadas situações que fazem parte da rotina dos profissionais inseridos naquele contexto. Uma delas é a comunicação com profissionais de outras áreas, como por exemplo, a Medicina. O livro aborda a importância da interlocução do psicólogo com esses profissionais, assim como a necessidade do conhecimento das doenças que afetam os pacientes com os quais irá lidar ou dos transtornos de aprendizagem e dinâmica escolar para, assim, poder intervir comportamentalmente.

Em cada capítulo, os autores apresentam a definição do tema a ser tratado e como a Análise do Comportamento pode ser aplicada em cada um dos contextos abordados. A linguagem utilizada é de fácil entendimento, principalmente por explorar temas que não são exclusivos da área da Psicologia, 
os autores conseguiram introduzir o tema sem muitas complicações, articulando com o papel do psicólogo, especificamente no que ele pode intervir e como deve interagir com outros profissionais. Para ilustrar os assuntos e a abordagem teórica utilizada, são descritos estudos recentes demonstrando a eficácia de intervenções realizadas, junto ao desenvolvimento de tecnologias analíticocomportamentais para viabilizar a atuação do psicólogo nesses contextos. Como se trata da aplicação da Análise do Comportamento em intervenções na saúde e na educação, alguns conceitos importantes utilizados por essa abordagem teórica são descritos ao longo dos capítulos. Porém, mesmo para os iniciantes ou para leitores que não são familiarizados com a perspectiva analítico-comportamental, é possível o entendimento dos processos descritos, pois os autores apresentam as definições desses termos de um modo breve e resumido, já articulado ao assunto que está sendo tratado no texto.

A obra consegue abranger uma ampla variedade de fenômenos tanto na área da saúde quanto na educação. Na área dermatológica, por exemplo, tratase a questão da emissão de comportamentos autolesivos em indivíduos com doenças de pele, assim como a adesão ao tratamento dessas doenças e, em uma perspectiva preventiva, como a valorização social da exposição ao sol e do bronzeamento pode ter consequências nocivas à saúde em longo prazo. Abordase esses fenômenos através da visão da Análise do Comportamento, da Medicina e da Psiquiatria. Ainda na área da saúde, especificamente na área pediátrica, descreve-se estratégias de intervenção comportamental com crianças em quimioterapia, com ênfase no conceito de comportamento governado por regras. Ainda no contexto pediátrico, a obra traz um capítulo com uma revisão de artigos sobre problemas de ingestão alimentar infantil, a fim de examinar e divulgar o conhecimento produzido sobre esse fenômeno, selecionando os periódicos que tratam de avaliações e intervenções com pacientes que apresentam problemas de ingestão alimentar. Foi realizado também um levantamento e análise bibliográfica a respeito da utilização de procedimento de reforço diferencial de comportamentos alternativos em saúde, que tem como objetivo a redução de comportamento inadequados e desenvolvimento de comportamentos alternativos considerados adequados. Esse procedimento contribui para o tratamento e prevenção de doenças, melhorando as condições de saúde e também a qualidade de vida do paciente.

Com relação a temas que vem sendo cada vez mais recorrentes e de interesse, principalmente, de psicólogos e pesquisadores da área, o livro aborda temas como o Autismo e a Ansiedade. Com relação ao Transtorno do Espectro do Autismo, trata-se especialmente da identificação de sinais precoces, no contexto das unidades básicas de saúde. Sobre a Ansiedade, há dois enfoques: um capítulo sobre o Transtorno de Ansiedade Social, que traz considerações gerais sobre essa condição, e um que descreve os transtornos de ansiedade e apresenta também estudos com intervenções comportamentais em grupo. Uma 
área da Análise do Comportamento que vem se desenvolvendo cada vez mais é a utilização de tecnologias comportamentais para intervenções em diversos âmbitos, sendo que a presente obra apresenta um capítulo sobre a utilização dessa tecnologia para pacientes com Alzheimer, por meio de estudos baseados no modelo de equivalência de estímulos, a fim de reduzir o esquecimento e auxiliar pessoas com a doença. Outra possibilidade de atuação do psicólogo é no ensino de habilidades, procedimento que foi descrito no capítulo sobre o ensino de comunicação a médicos, pacientes e acompanhantes. Considerando que o ambiente hospitalar se caracteriza, muitas vezes, por incertezas, sofrimento e situações estressoras tanto para os pacientes quanto para os profissionais envolvidos, é de extrema importância que haja uma comunicação efetiva entre eles, o que pode ter resultados positivos tanto para o estado emocional dessas pessoas quanto para a adesão ao tratamento.

No contexto dos fenômenos da área educacional, especificamente no capítulo "Ensino de precisão de leitura em crianças com desenvolvimento típico", os autores descrevem como os analistas do comportamento entendem a aprendizagem e como ela ocorre segundo essa perspectiva teórica, desenvolvendo assim estratégias para auxiliar os estudantes que apresentam alguma dificuldade em aprender. $O$ texto traz de modo claro e resumido essa visão e apresenta estudos e intervenções que vem sendo realizadas através da utilização de estratégias desenvolvidas por analistas do comportamento, assim como seus resultados. No capítulo "Algumas contribuições da Psicologia para a Educação", além de conceituar e fazer um resumo da história da Educação, a autora parte das questões recorrentes no campo educacional para assim articular quais desses aspectos poderiam ser foco de intervenção do psicólogo. É um texto rico em informações para quem se interessa pela área da Educação, sejam profissionais da Psicologia ou de outras áreas que atuam nesse contexto, ao ampliar o entendimento dos processos que ocorrem tanto em sala de aula quanto em nível institucional. O capítulo apresenta dados sobre quais temas vêm sendo mais estudados nesse campo e possibilita a reflexão da importância da educação para o desenvolvimento do ser humano, das possibilidades de inserção do psicólogo nesse meio e da necessidade da realização e publicação de estudos sobre os diversos fatores que fazem parte da Educação. Para quem se interessa pela área de Programação de Ensino, o capítulo "Intervenção do psicólogo como capacitador de professores: Algumas reflexões sobre o ponto de partida desse tipo de atuação", traz essa subárea da Análise do Comportamento, que possui múltiplas possibilidades de aplicação, de modo detalhado e com esquemas didáticos, a fim de exemplificar como é feito o planejamento de uma intervenção do psicólogo como capacitador, nesse caso, de professores. O capítulo "Análise funcional das habilidades sociais educativas apresentadas por pais de crianças com TDAH" mostra a importância do entendimento do ambiente no qual essas crianças se desenvolvem, e descreve um estudo para treino de comportamentos 
referentes a habilidades sociais educativas, a partir da análise funcional realizada. O último capítulo também apresenta um estudo com treino de habilidades: "Treinamento de habilidades psicológicas no esporte: Um estudo de caso com atletas de taekwondo", descrevendo os objetivos e procedimentos de ensino utilizados para diminuir as queixas iniciais apresentadas pelos atletas, como nervosismo, pressão por resultados, ansiedade, cansaço, entre outros. O ensino e treino de habilidades oferece uma ampla possibilidade de atuação do psicólogo, visto a aplicabilidade de diferentes princípios comportamentais para as mais diversas situações, seja na escola, no ambiente familiar, esporte, contexto hospitalar, organizacional, e assim por diante.

Partindo de conceitos básicos da Análise do Comportamento e demonstrando como ocorre a sua utilização para intervenções no contexto da saúde e no contexto educacional, a obra consegue relacionar teoria e prática, mostrando a importância do estudo dos processos básicos que regem o comportamento humano, e suas implicações práticas. Muitas vezes na graduação, os estudantes não conseguem entender o motivo de estudarem tantos conceitos que, à primeira vista, podem parecer distantes da atuação profissional. Isso faz com que a leitura de obras como esta seja indispensável, visto que demonstra a ocorrência dos processos básicos do comportamento humano nos mais variados contextos e as formas com as quais pode-se utilizar os princípios comportamentais a fim de programar intervenções em quaisquer contextos que se fizerem necessárias. Além disso, a leitura da obra não se restringe aos profissionais ou estudantes da Psicologia, sendo recomendada para profissionais de diferentes áreas, auxiliando-os no entendimento da multideterminação dos fenômenos com os quais eles lidam diariamente, e também dando condições para que possam aprender a lidar com situações que muitas vezes, requerem habilidades que não Ihes foram ensinadas e, assim, dispor de um maior número de informações para que sua atuação seja ainda mais efetiva e satisfatória.

\section{Sobre a autora}

Fernanda Torres Sahão é graduanda do quinto ano de Psicologia pela Universidade Estadual de Londrina, participou de pesquisas na área de programação de ensino e está finalizando um projeto de Iniciação Científica que tem como objetivo avaliar o desempenho de agentes comunitárias de saúde em intervenções junto a mulheres usuárias de produtos derivados do tabaco. ftsahao@gmail.com

Recebido em: 25/07/2016 Aceito em: 27/07/2016 